\title{
Gebruik en kosten van jeugdzorg door jeugdigen met een Turkse of Marokkaanse achtergrond
}

\author{
Klarita Sadiraj · Freek Bucx · Michiel Ras
}

Published online: 26 November 2019

(c) The Author(s) 2019

\begin{abstract}
Samenvatting Jeugdigen met een Turkse of Marokkaanse achtergrond maken minder vaak gebruik van vrijwillige jeugdzorg dan autochtone jeugdigen, maar komen juist vaker terecht in de gedwongen jeugdzorg. Doel van dit onderzoek is meer zicht te krijgen op een verklaring hiervoor door ook naar de zorgkosten te kijken. We maken gebruik van informatie uit registraties van onder andere jeugdhulpaanbieders uit 2012. De gemiddelde kosten van vrijwillige jeugdzorg blijken voor jeugdigen met een Turkse of Marokkaanse achtergrond hoger te zijn dan voor autochtone jeugdigen, terwijl die van gedwongen jeugdzorg juist lager liggen. Dit wijst erop dat de problemen waarvoor jeugdigen met een Turkse of Marokkaanse achtergrond in het vrijwillige circuit zorg ontvangen, relatief zwaar zijn, en de problemen in de gedwongen zorg juist lichter dan bij autochtone jeugdigen. We geven mogelijke verklaringen voor de aangetroffen verschillen.
\end{abstract}

Trefwoorden jeugdzorg $\cdot$ niet-westers $\cdot$ vrijwillige zorg $\cdot$ gedwongen kader

\section{Use and costs of youth care by children with a Turkish or Moroccan background}

\begin{abstract}
Compared to native Dutch children, children with a Turkish or Moroccan background make less use of voluntary youth care though are overrepresented in compulsory youth care. In order to understand these differences, the current study not only investigates the use but also the cost of youth care for different ethnic groups, using register data from Statistics Netherlands. The costs of voluntary youth care for children with a Turkish or Moroccan background
\end{abstract}

\section{K. Sadiraj $(\varangle) \cdot$ F. Bucx $\cdot$ M. Ras}

Sociaal en Cultureel Planbureau, Den Haag, Nederland k.sadiraj@scp.nl are higher than that provided to native Dutch children, though the costs of compulsory youth care are lower. This suggests that the developmental problems of children with a Turkish or Moroccan background who use voluntary youth care are more severe than those of native Dutch children using voluntary youth care, while the problems of children with a Turkish or Moroccan background using compulsory youth care are less severe. Possible explanations for the results are discussed.

Keywords youth care $\cdot$ non-western - voluntary care compulsory youth care

\section{Inleiding}

Jeugdzorg is de verzamelnaam voor jeugdhulp, jeugdbescherming en jeugdreclassering. In 2017 maakte bijna een op de tien jeugdigen gebruik van jeugdzorg

\section{Kernpunten}

- Jeugdigen met een Turkse of Marokkaanse achtergrond maken minder vaak gebruik van vrijwillige jeugdzorg dan autochtone jeugdigen, maar komen juist vaker terecht in de gedwongen jeugdzorg.

- De gemiddelde kosten van vrijwillige jeugdzorg blijken voor jeugdigen met een Turkse of Marokkaanse achtergrond hoger te zijn dan voor autochtone jeugdigen, terwijl die van gedwongen jeugdzorg juist lager liggen.

- Dit wijst erop dat de problemen waarvoor jeugdigen met een Turkse of Marokkaanse achtergrond in het vrijwillige circuit zorg ontvangen, relatief zwaar zijn, en de problemen in de gedwongen zorg juist lichter dan bij autochtone jeugdigen. 
[1]. Dit betreft vooral vrijwillige jeugdzorg (jeugdhulp; 1 op de 12 jeugdigen) en in mindere mate gedwongen jeugdzorg (jeugdbescherming en -reclassering; 1 op de 70 jeugdigen). Jeugdigen met een niet-westerse achtergrond maken gemiddeld genomen minder vaak gebruik van jeugdzorg dan hun autochtone leeftijdgenoten [2]. Binnen deze niet-westerse groep bestaan er echter grote verschillen. Jeugdigen met een Surinaamse of Antilliaanse achtergrond ontvangen juist vaker jeugdzorg dan autochtone leeftijdgenoten [2, 3]. Bij jeugdigen met een Turkse of Marokkaanse achtergrond ligt het anders: zij ontvangen juist minder vaak vrijwillige jeugdzorg dan andere groepen jeugdigen, maar komen wel vaker terecht in het zogenoemde gedwongen kader.

Het hogere gebruik van jeugdzorg door jeugdigen met een Surinaamse of Antilliaanse achtergrond valt goed te verklaren. Bij deze groepen jeugdigen ligt de prevalentie van emotionele en gedragsproblemen immers ook hoger $[4,5]$. Ook risicofactoren als alleenstaand ouderschap en armoede komen vaker voor [6].

Het lagere gebruik van vrijwillige jeugdzorg door jeugdigen van Turkse of Marokkaanse herkomst is lastiger te begrijpen. Ook bij hen is er namelijk sprake van een hogere prevalentie van problemen [4, 7]. Zij hebben vaker gedragsproblemen dan autochtone leeftijdgenoten [4, 7], en ook emotionele problemen komen, vooral bij Turks-Nederlandse meisjes, vaker voor [4]. Deze hogere prevalentie bij kinderen met een Turkse of Marokkaanse achtergrond hangt samen met een grotere aanwezigheid van risicofactoren die de kans op problemen vergroten, zoals armoede: een kwart respectievelijk een derde van hen groeit op in armoede [6].

Vanwege de problematiek en de aanwezigheid van risicofactoren zou men verwachten dat ook het gebruik van de vrijwillige jeugdzorg in de Turkse en Marokkaanse groepen hoger is. Maar dat is dus niet het geval - integendeel. Hun ondervertegenwoordiging in de vrijwillige jeugdzorg wordt mogelijk verklaard door een terughoudende opstelling om zich bij problemen tot experts te richten $[3,8]$. Ouders met een niet-westerse achtergrond zijn relatief vaak van mening dat zij geen invloed hebben op problemen [3]. Bovendien rust er bij deze groepen dikwijls een taboe op het vragen om hulp bij problemen [9] en spelen gevoelens van schaamte een rol [8]. Ook lijken vooral Turks-Nederlandse en Marokkaans-Nederlandse ouders weinig vertrouwen te hebben in overheidsinstanties [9] en is het door taalbarrières voor hen minder gemakkelijk om hulp te vinden [10].

Aanwijzingen voor de geldigheid van deze verklaringen zouden gevonden kunnen worden door niet alleen naar het gebruik te kijken, maar ook naar de kosten per gebruiker. Als men al vrijwillig op zoek gaat naar hulp, doet men dat pas op een later moment, zo valt te verwachten: wanneer problemen al langere tijd bestaan of in ernst zijn toegenomen. Mogelijk kan dan niet meer volstaan worden met een lichte vorm van hulp, maar zal er ook vaker zwaardere - en daarmee duurdere - hulp nodig zijn. Het gevolg kan zijn dat de kosten van vrijwillige jeugdzorg per gebruiker hoger liggen.

Voor de kosten van gedwongen hulp geldt mogelijk een ander verhaal. De terughoudende opstelling van Turkse en Marokkaanse gezinnen kan ertoe leiden dat er bij deze groepen - vergeleken met autochtone Nederlanders - bij vergelijkbare problemen eerder tussenkomst van een rechter noodzakelijk is: in dat geval zou een gedwongen maatregel bij Turkse en Marokkaanse groepen bij relatief lichte problemen ingezet worden, met relatief lichte - en daarmee ook vaak minder dure - vormen van hulp. Dat zou betekenen dat de kosten per gebruiker van gedwongen hulp voor deze groepen juist lager liggen.

\section{Doel van het onderzoek}

Wij wilden onderzoeken hoe het gebruik en de kosten van jeugdzorg verschillen tussen jeugdigen met een Turkse of Marokkaanse achtergrond en autochtone jeugdigen. Hierbij kijken we ook in hoeverre verschillen in gebruik en kosten verklaard worden door verschillen in risicofactoren bij het kind (geslacht, leeftijd) en het gezin (samenstelling, grootte, ggz-gebruik door de ouder(s), gezinsinkomen). Uit eerder onderzoek blijkt namelijk dat deze risicofactoren samenhangen met probleemgedrag en met het gebruik van jeugdzorg. Zo krijgen kinderen met het toenemen van de leeftijd meer problemen [3], lopen jongens een groter risico om (gedrags)problemen te ontwikkelen en om in de jeugdzorg te belanden dan meisjes [3], is het risico op probleemgedrag groter in eenoudergezinnen dan in tweeoudergezinnen [5], en hebben kinderen een grotere kans op problemen naarmate het gezinsinkomen lager is [11] en ouders zelf psychische problemen hebben [12].

In zowel de vrijwillige als de gedwongen jeugdzorg kan de zorg ambulant gegeven worden - dan spreken we ook wel van 'zorg zonder verblijf' - en residentieel - 'zorg met verblijf'. De zorg zonder verblijf kan over het algemeen gezien worden als een relatief lichtere vorm en de zorg met verblijf als een relatief zwaardere vorm van zorg. In aanvullende analyses maken we om twee redenen onderscheid tussen 'zorg zonder verblijf' en 'zorg met verblijf'. Ten eerste onderzoeken we onze impliciete aanname dat er een (positieve) relatie bestaat tussen de zwaarte en de kosten van de zorg. En ten tweede kijken we naar verschillen tussen jeugdigen met een Turkse of Marokkaanse achtergrond en autochtone jeugdigen in (de kans op) gebruik van zorg zonder en zorg met verblijf. 


\section{Methode}

\section{Gegevens}

We analyseerden registratiegegevens over alle kinderen in Nederland jonger dan 18 jaar in 2012 (recentere gegevens zijn niet beschikbaar) [13]. Deze gegevens zijn aan het Centraal Bureau voor de Statistiek (CBS) verstrekt door zorgverzekeraars (gebruik en kosten van zorg door jeugdigen, alsook gebruik door hun ouders), de Gemeentelijke Basisadministratie (etnische herkomst, leeftijd en geslacht van het kind, samenstelling en grootte van het gezin) en de Belastingdienst (gezinsinkomen).

\section{Variabelen}

Afhankelijke variabelen waren gebruik en kosten. Op basis van de informatie afkomstig uit de provinciale jeugdzorg, langdurige AWBZ-zorg, kortdurende ggz-zorg (het ggz-zorggebruik is afkomstig uit 2011) en jeugdzorg plus is het gebruik van jeugdzorg bepaald. In de analyses hebben we onderscheid gemaakt tussen 1) jeugdigen die geen jeugdzorg ontvangen; 2) jeugdigen met alleen vrijwillige jeugdzorg; en 3) jeugdigen met gedwongen jeugdzorg (eventueel in combinatie met vrijwillige zorg). Op basis van dezelfde gegevens is bepaald of de jeugdzorg ambulant dan wel residentieel was, en daarmee of het zorg zonder of met verblijf was.

De kosten (in euro's per gebruiker) werden berekend door het zorgvolume van alle verschillende zorgvormen (in termen van dagen) te vermenigvuldigen met de dagprijs. De dagprijs werd bepaald op basis van NZa-tarieven (AWBZ, DBC), beschikbare budgetten of tarieven voor een bepaalde zorgvorm (provinciale jeugdzorg) en kosten uit de zorgverzekeraarsadministratie [13].

De onafhankelijke variabele betreft de etnische herkomst van de jeugdigen, die is bepaald op basis van het geboorteland van de ouders: autochtoon, Turks of Marokkaans. Voor de volledigheid onderscheiden we in de tabellen ook een groep overig, die jeugdigen met een andere etnische achtergrond bevat, waaronder Surinaams en Antilliaans. Uitkomsten voor deze groep bespreken we echter niet omdat we ons in dit artikel richten op verschillen tussen jeugdigen met een autochtone, Turkse en Marokkaanse achtergrond.

Risicofactoren. We controleerden voor leeftijd en geslacht van de jeugdigen, en voor samenstelling (tweeoudergezin versus eenoudergezin) en grootte van het gezin (drie kinderen of minder versus meer dan drie kinderen), gebruik van de ggz-zorg door (een van beide) ouder(s) en het gezinsinkomen. Wanneer het inkomen gelijk was aan of lager lag dan de armoedegrens [14], was er sprake van een laag inkomen, anders van een midden/hoog inkomen.
Analyses

De kans op gebruik is geschat op basis van multinomiale logitanalyses. Kosten zijn geschat met multivariate lineaire regressie, voor gebruikers van vrijwillige en gedwongen zorg afzonderlijk. Er zijn telkens twee modellen geschat: model 1 bevat alleen etnische herkomst en model 2 daarnaast ook de risicofactoren.

\section{Resultaten}

\section{Beschrijvende resultaten}

Tabel 1 geeft het gebruik en de kosten weer voor elke herkomstgroep. Van alle jeugdigen met een Turkse of Marokkaanse achtergrond maakte 5,6\% in 2012 gebruik van vrijwillige jeugdzorg; het gebruik is lager dan dat van autochtone jeugdigen $(9,0 \%)$. De kosten van deze hulp per gebruiker lagen voor jeugdigen met een Turkse of Marokkaanse achtergrond (circa 8.500 euro) hoger dan voor autochtone jeugdigen (circa 6.700 euro).

Ongeveer 2,1\% van de jeugdigen met een Turkse of Marokkaanse achtergrond had gedwongen hulp; dat is meer dan bij de autochtone jeugdigen $(1,1 \%)$. De kosten van gedwongen hulp voor deze groepen (ongeveer 23.000 euro) lagen fors lager dan voor de autochtone groep (bijna 30.000 euro).

\section{Verschillen in gebruik en kosten}

Om de correctie voor risicofactoren te verduidelijken, presenteren we eerst model 1 in tab. 2 (gebruik) en tab. 3 (kosten). Model 1 geeft in feite de beschrijvende resultaten nogmaals weer, maar dan in termen van de te gebruiken logit- en regressieanalyses. Vergeleken met autochtone jeugdigen ontvangen jeugdigen met een Turkse of Marokkaanse achtergrond minder vaak vrijwillige zorg (relative risk ratio=0,60, zie tab. 2, model 1) en zijn de kosten van vrijwillige zorg hoger $(b=1.442$ respectievelijk 2.106; zie tab. 3, model 1). Verder ontvangen jeugdigen met een Turkse of Marokkaanse achtergrond vaker gedwongen zorg dan autochtone jeugdigen (relative risk ratio $=1,59$ respectievelijk 1,96; zie tab. 2, model 1), maar vergeleken met autochtone jeugdigen liggen de kosten van ge-

Tabel 1 Gebruik (in procenten) en kosten (gemiddeld per gebruiker, in euro's $\times 1.000$ ) van jeugdzorg, naar etnische herkomst, 2012

\begin{tabular}{|c|c|c|c|c|}
\hline & \multicolumn{2}{|l|}{ Gebruik } & \multicolumn{2}{|l|}{ Kosten } \\
\hline & Vrijwillig & Gedwongen & Vrijwillig & Gedwongen \\
\hline Turks & 5,6 & 1,9 & 8,2 & 22,5 \\
\hline Marokkaans & 5,6 & 2,3 & 8,8 & 23,7 \\
\hline Autochtoon & 9,0 & 1,1 & 6,7 & 29,6 \\
\hline Overig & 7,1 & 2,5 & 8,2 & 27,7 \\
\hline
\end{tabular}


Tabel 2 Kans op gebruik van twee typen jeugdzorg (vergeleken met kans op niet-gebruik), naar etnische herkomst (relative risk ratio's)

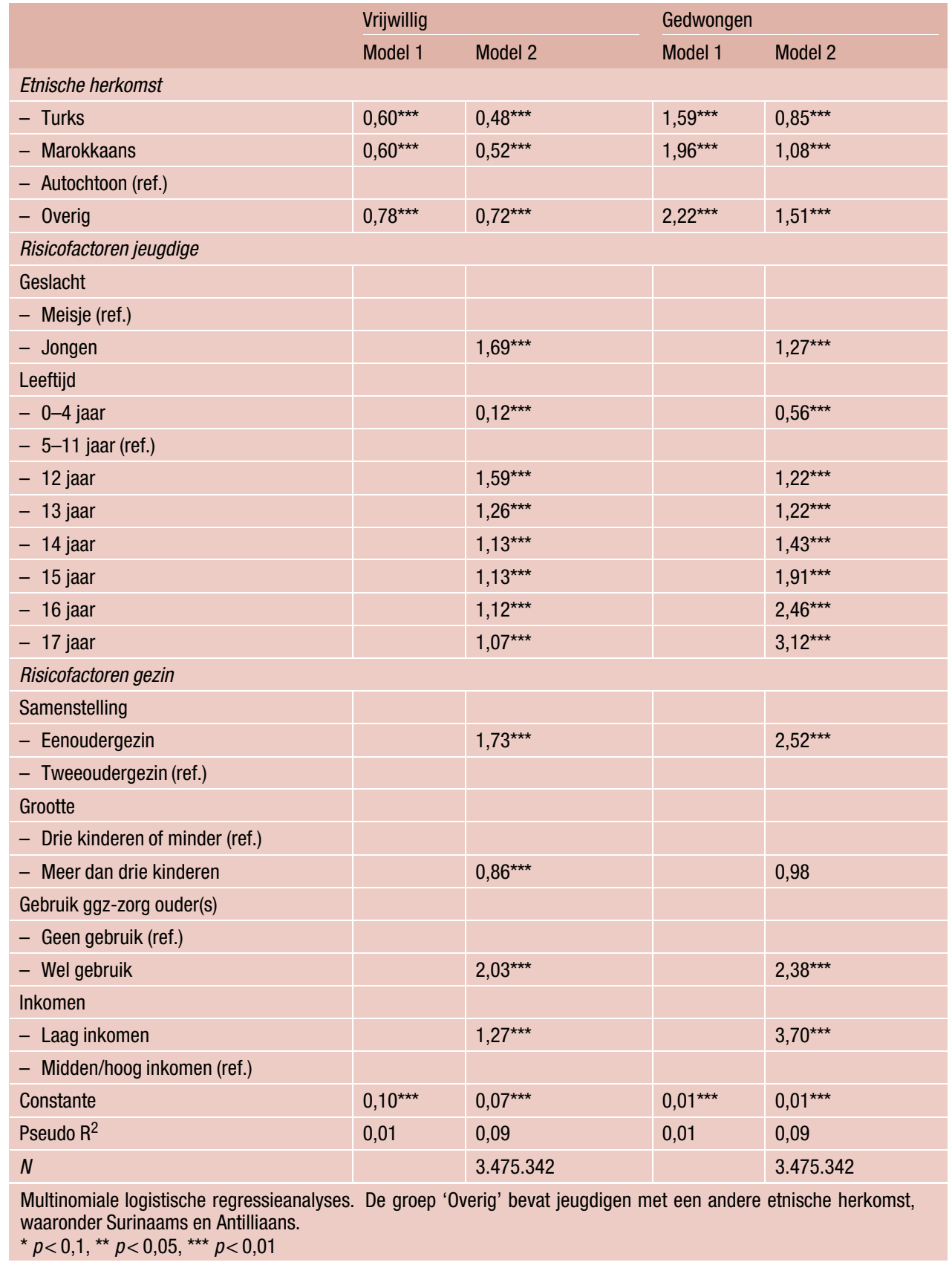

dwongen zorg lager voor jeugdigen met een Turkse of Marokkaanse achtergrond $(b=-7.091$ respectievelijk -5.875, zie tab. 3, model 1).

\section{Correctie voor risicofactoren}

In model 2 is gecorrigeerd voor risicofactoren. De meeste risicofactoren vergroten de kans op gebruik van jeugdzorg. De relatie tussen de risicofactoren en de kosten is soms anders. Zie tab. 2 en 3 (model 2) voor de uitkomsten.

Na correctie voor de risicofactoren ontvangen jeugdigen met een Turkse of Marokkaanse achtergrond nog steeds minder vaak vrijwillige jeugdzorg dan autochtone jeugdigen (relative risk ratio $=0,48$ respectie- velijk 0,52, zie tab. 2, model 2) - het verschil is zelfs iets groter geworden. Verschillen in de kosten van vrijwillige zorg worden deels wel door risicofactoren verklaard. Toch blijven de kosten voor jeugdigen met een Turkse of Marokkaanse achtergrond na correctie hoger dan voor autochtone jeugdigen ( $b=488$ respectievelijk 1.056, zie tab. 3, model 2).

De verschillen in gebruik van gedwongen zorg tussen autochtone jeugdigen en jeugdigen met een Marokkaanse achtergrond worden juist grotendeels verklaard door risicofactoren; de laatste groep is na correctie slechts licht oververtegenwoordigd in de gedwongen zorg (relative risk ratio $=1,08$, zie tab. 2, model 2). Het beeld is anders voor jeugdigen met een Turkse achtergrond: deze komen na correctie voor 


\section{Wetenschappelijk artikel}

Tabel 3 Gemiddelde kosten per gebruiker van twee typen jeugdzorg, naar etnische herkomst (ongestandaardiseerde coëfficiënten)

\begin{tabular}{|c|c|c|c|c|}
\hline & \multicolumn{2}{|l|}{ Vrijwillig } & \multicolumn{2}{|l|}{ Gedwongen } \\
\hline & Model 1 & Model 2 & Model 1 & Model 2 \\
\hline \multicolumn{5}{|l|}{ Etnische herkomst } \\
\hline - Turks & $1.442^{\star \star \star}$ & $488^{\star \star \star}$ & $-7.091^{\star \star \star}$ & $-8.681^{\star \star \star}$ \\
\hline - Marokkaans & $2.106^{\star \star \star}$ & $1.056^{\star \star \star}$ & $-5.875^{\star \star \star}$ & $-5.598^{\star \star \star}$ \\
\hline \multicolumn{5}{|l|}{ - Autochtoon (ref.) } \\
\hline - Overig & $1.443^{\star \star \star}$ & $953^{\star \star \star}$ & $-1.935^{\star \star \star}$ & $-1.163^{\star \star \star}$ \\
\hline \multicolumn{5}{|l|}{ Risicofactoren jeugdige } \\
\hline \multicolumn{5}{|l|}{ Geslacht } \\
\hline \multicolumn{5}{|l|}{ - Meisje (ref.) } \\
\hline - Jongen & & $826^{\star \star \star}$ & & 406 \\
\hline \multicolumn{5}{|l|}{ Leeftijd } \\
\hline - 0-4 jaar & & $5.199^{\star \star \star}$ & & $-7.651^{\star \star \star}$ \\
\hline \multicolumn{5}{|l|}{ - 5-11 jaar (ref.) } \\
\hline-12 jaar & & $-414^{\star \star \star}$ & & $4.614^{\star \star \star}$ \\
\hline-13 jaar & & -1 & & $6.237^{\star \star \star}$ \\
\hline - 14 jaar & & $821^{\star \star \star}$ & & $8.203^{\star \star \star}$ \\
\hline-15 jaar & & $1.674^{\star \star \star}$ & & $11.164^{\star \star \star}$ \\
\hline-16 jaar & & $2.485^{\star \star \star}$ & & $12.052^{\star \star \star}$ \\
\hline - 17 jaar & & $3.312^{\star \star \star}$ & & $13.011^{\star \star \star}$ \\
\hline \multicolumn{5}{|l|}{ Risicofactoren gezin } \\
\hline \multicolumn{5}{|l|}{ Samenstelling } \\
\hline - Eenoudergezin & & -17 & & $-9.568^{\star \star \star}$ \\
\hline \multicolumn{5}{|l|}{ - Tweeoudergezin (ref.) } \\
\hline \multicolumn{5}{|l|}{ Grootte } \\
\hline \multicolumn{5}{|c|}{ - Drie kinderen of minder (ref.) } \\
\hline - Meer dan drie kinderen & & -60 & & $-12.323^{\star \star \star}$ \\
\hline \multicolumn{5}{|l|}{ Gebruik ggz-zorg ouder(s) } \\
\hline \multicolumn{5}{|l|}{ - Geen gebruik (ref.) } \\
\hline - Wel gebruik & & $1.677^{\star \star \star}$ & & $1.166^{\star \star \star}$ \\
\hline \multicolumn{5}{|l|}{ Inkomen } \\
\hline - Laag inkomen & & $2.018^{\star \star \star}$ & & 732 \\
\hline \multicolumn{5}{|c|}{ - Midden/hoog inkomen (ref.) } \\
\hline Constante & $6.727^{\star \star \star}$ & $4.595^{\star \star \star}$ & $29.595^{\star \star \star}$ & $29.629^{\star \star \star}$ \\
\hline $\mathrm{R}^{2}$ & 0,00 & 0,02 & 0,00 & 0,07 \\
\hline$N$ & 294.391 & 294.391 & 49.846 & 49.846 \\
\hline
\end{tabular}

risicofactoren juist wat minder vaak terecht in de gedwongen hulp (relative risk ratio $=0,85$, zie tab. 2 , model 2). Voor de verschillen in kosten van gedwongen zorg maakt de opname van risicofactoren weinig uit: ook na correctie zijn de kosten voor jeugdigen met een Turkse of Marokkaanse achtergrond fors lager dan voor autochtone jeugdigen ( $b=-8.681$ respectievelijk -5.598 , zie tab. 3, model 2).

\section{Zorg zonder verblijf en zorg met verblijf}

In aanvullende analyses (niet in de tabellen) hebben we onderscheid gemaakt naar zorg zonder en zorg met verblijf. De specifieke uitkomsten van deze aanvul- lende analyses zijn op te vragen bij de auteurs. Hier bespreken we alleen de belangrijkste conclusies.

Ten eerste hebben we de gemiddelde kosten voor deze soorten zorg in kaart gebracht. Onze analyses laten zien dat - voor zowel de vrijwillige zorg als de gedwongen zorg - de gemiddelde kosten van zorg met verblijf hoger liggen dan die van zorg zonder verblijf. Ervanuit uitgaande dat zorg met verblijf over het algemeen een zwaardere soort zorg betreft dan zorg zonder verblijf, biedt dit ondersteuning voor onze impliciete aanname dat er een (positieve) relatie is tussen de zwaarte van de zorg en de kosten.

Verder hebben we aanvullend gekeken naar verschillen tussen jeugdigen met een Turkse of Marokkaanse achtergrond en autochtone jeugdigen wat be- 
treft (de kans op) gebruik van zorg zonder en zorg met verblijf. Deze analyses laten onder andere zien dat de kans op gedwongen zorg zonder verblijf groter is voor Turkse en Marokkaanse jeugdigen dan voor autochtone jeugdigen, terwijl de kans op gedwongen zorg met verblijf juist kleiner is. Onder de aanname dat de zorg met verblijf zwaarder is dan de zorg zonder verblijf zijn deze uitkomsten voor gedwongen zorg in lijn met wat we zouden kunnen verwachten op basis van de theoretische uiteenzetting in de inleiding van dit artikel, en daarmee ook met onze uitkomsten voor het gebruik en de zorgkosten. Bij vrijwillige zorg zijn de resultaten voor zorg met en zonder verblijf minder eenduidig.

\section{Beschouwing}

We constateerden dat jeugdigen met een Turkse of Marokkaanse achtergrond minder vaak vrijwillige jeugdzorg ontvangen dan hun autochtone leeftijdgenoten, en dat de gemiddelde kosten juist hoger liggen. Het beeld bleek omgekeerd voor de gedwongen zorg: Turkse en Marokkaanse jeugdigen komen vaker terecht in de gedwongen zorg dan hun autochtone leeftijdgenoten, maar de kosten liggen lager. Deze verschillen in gebruik en kosten tussen Turkse en Marokkaanse jeugdigen en autochtone jeugdigen konden slechts deels verklaard worden door risicofactoren.

Dat jeugdigen met een Turkse of Marokkaanse achtergrond ondervertegenwoordigd zijn in de vrijwillige jeugdzorg maar oververtegenwoordigd zijn in de gedwongen jeugdzorg, is bekend uit eerder onderzoek $[3,15]$. Vooral dat eerste is opvallend gezien de hogere prevalentie van gedrags- en emotionele problemen bij kinderen met een Turkse of Marokkaanse achtergrond $[4,7]$. Een mogelijke verklaring voor de ondervertegenwoordiging in de vrijwillige zorg vormt de veronderstelling dat Turks-Nederlandse en Marokkaans-Nederlandse kinderen en hun ouders relatief laat in contact komen met de jeugdzorg als gevolg van taal- en/of culturele barrières: namelijk op het moment dat problemen inmiddels uitgegroeid zijn tot relatief zware problemen, die ook een relatief dure oplossing vergen.

Onze bevinding dat de zorgkosten van vrijwillige zorg voor jeugdigen met een Turkse of Marokkaanse achtergrond hoger liggen dan voor autochtone jeugdigen, biedt ondersteuning voor een dergelijke gedachtegang. De verschillen in zorgkosten doen namelijk vermoeden dat de zorg die jeugdigen met een Turkse of Marokkaanse achtergrond in het vrijwillige circuit ontvangen, intensiever is dan de zorg die autochtone leeftijdgenoten krijgen. En dat wijst er op zijn beurt op dat de problemen waarvoor deze jeugdigen zorg krijgen, ook zwaarder zijn.

Langs dezelfde redeneerlijn ondersteunen onze bevindingen over de gedwongen hulp de gedachte dat jeugdigen met een Turkse of Marokkaanse achtergrond juist in een relatief vroeg stadium in de gedwongen hulp terechtkomen: dat zou namelijk verklaren waarom deze jeugdigen vaker terechtkomen in de gedwongen hulp, en de hulp per gebruiker minder kost. Ook de uitkomsten van de analyses waarin we onderscheid hebben gemaakt naar zorg met en zorg zonder verblijf passen in dit beeld, namelijk dat een gedwongen maatregel bij Turkse en Marokkaanse groepen bij relatief lichte zorg en lichte problemen ingezet wordt.

Dat jeugdigen met een Marokkaanse of Turkse achtergrond eerder in de gedwongen zorg terecht zouden komen, kan met verschillende zaken te maken hebben. Een mogelijke verklaring is dat deze jeugdigen en gezinnen niet snel zelf hulp zoeken, bijvoorbeeld als gevolg van schaamtegevoelens of omdat ze weinig vertrouwen hebben in de hulp die geboden wordt $[3,8$, 9]. Een dergelijke terughoudende opstelling zou kunnen verklaren waarom gedwongen hulp juist eerder ingezet wordt: namelijk omdat de kans kleiner is dat hulp zonder een gedwongen maatregel door de jeugdige zelf of zijn of haar gezin aangenomen wordt. Dat gedwongen hulp eerder wordt ingezet zou echter ook te maken kunnen hebben met communicatieproblemen tussen deze jeugdigen en hun gezin aan de ene kant en de hulpverlening en de rechterlijke macht aan de andere kant, waardoor een gedwongen maatregel door de laatste groep eerder als noodzakelijk wordt beschouwd.

Opmerkelijk was onze bevinding dat jeugdigen met een Turkse achtergrond na correctie voor risicofactoren juist iets minder vaak terechtkomen in de gedwongen hulp dan autochtone jeugdigen. Mogelijk spelen hier de hechte banden binnen de Turks-Nederlandse gemeenschap een rol [2]: Turkse Nederlanders leven vaak in hechte netwerken bestaande uit leden met dezelfde culturele achtergrond, en daarvan kan een beschermende invloed uitgaan [16]. Zo zijn er aanwijzingen dat dit (mede) verklaart waarom de criminaliteitscijfers onder Turkse Nederlanders vaak lager zijn dan onder andere Nederlanders met een niet-westerse migratieachtergrond [2]. Mogelijk geldt hetzelfde voor de instroom in de gedwongen zorg.

Onze bevindingen ondersteunen de gedachte dat er minder snel vrijwillige hulp is en juist sneller gedwongen hulp bij jeugdigen met een Turkse of Marokkaanse achtergrond. Mogelijk betekent dit dat deze ouders en hun kinderen relatief laat met jeugdzorg in contact komen, waardoor relatief lichte opgroeien opvoedproblemen verergeren, en waardoor later zwaardere en duurdere vormen van hulp nodig zijn. Bedenk echter dat andere verklaringen voor de gevonden patronen niet uitgesloten kunnen worden. Dat vrijwillige hulp aan jeugdigen met een Turkse of Marokkaanse achtergrond duurder is, kan bijvoorbeeld ook veroorzaakt worden door taalproblemen of culturele barrières, waardoor de hulp minder goed aansluit en langer duurt. Nader onderzoek hiernaar zou in de toekomst kunnen worden uitgevoerd met een longitudinaal onderzoeksontwerp, waarbij personen gedu- 
rende een langere periode worden gevolgd. Ten slotte baseren we onze bevindingen op gegevens uit 2012; meer recente gegevens waren niet beschikbaar. Het is niettemin aan te bevelen om te onderzoeken in hoeverre het geschetste beeld ook geldt voor de huidige situatie, na invoering van de Jeugdwet in 2015.

Open Access This article is distributed under the terms of the Creative Commons Attribution 4.0 International License (http://creativecommons.org/licenses/by/4.0/), which permits unrestricted use, distribution, and reproduction in any medium, provided you give appropriate credit to the original author(s) and the source, provide a link to the Creative Commons license, and indicate if changes were made.

\section{Literatuur}

1. Centraal Bureau voor de Statistiek. Jeugdhulp 2017. Den Haag, Heerlen, Bonaire: Centraal Bureau voor de Statistiek; 2018.

2. Staring RHJM, Geelhoed F, Aslanoglu G, et al. Ontwikkelingen in de maatschappelijke positie van Turkse Nederlanders. Den Haag: Boom, Lemma; 2014.

3. BotS, Roos S de, Sadiraj K, etal. Terecht in dejeugdzorg. Den Haag: Sociaal en Cultureel Planbureau; 2013.

4. Gezondheidsraad. Psychische gezondheid en zorggebruik van migrantenjeugd. Den Haag: Gezondheidsraad; 2012.

5. Looze M de, Dorsselaer S van, Roos S de, et al. HBSC. Gezondheid, welzijn en opvoeding van jongeren in Nederland. Utrecht, Den Haag: Universiteit Utrecht, Trimbos Instituut, Sociaal en Cultureel Planbureau; 2014.

6. Bucx F, Roos S de. Opvoeden in niet-westerse migrantengezinnen. Den Haag: Sociaal en Cultureel Planbureau; 2015.
7. Adriaanse M, Veling W, Dorelijers T, Domburgh L van. The link between ethnicity, social disadvantage and mental health problems in a school-based multiethnic sample of children in the Netherlands. Eur Child Adolesc Psychiatry. 2014;23:1103-13.

8. Broek A van den, Kleijnen E, Keuzenkamp S. Naar Hollands gebruik? Verschillen in gebruik van hulp bij opvoeding, onderwijs en gezondheid tussen autochtonen en migranten. Den Haag: Sociaal en Cultureel Planbureau; 2010.

9. Distelbrink M. Ondersteuning van opvoeders in Amsterdam Noord, Slotervaart en Zuidoost: praktijk, beleid en migrantenorganisaties. Inventarisatie voor de kenniswerkplaats Tienplus. Utrecht: Verwey-Jonker Instituut; 2009.

10. Kalthoff H. Opvoedingsondersteuning aan migrantengezinnen schiet tekort. Jeugd Kennis. 2009;4:8-18.

11. Piotrowska PJ, Stride CB, Croft SE, Rowe R. Socioeconomic status and antisocial behaviour among children and adolescents: a systematic review and meta-analysis. Clin Psychol Rev. 2015;35:47-55.

12. Hancock KJ, Mitrou F, Shipley M, Lawrence D, Zubrick SR. A three generation study of the mental health relationships between grandparents, parents and children. BMC Psychiatry. 2013;13:299.

13. PommerE, SadirajK. Verdelinghistorischemiddelenjeugdzorg in 2012. Den Haag: Sociaal en Cultureel Planbureau; 2014.

14. Centraal Bureau voor de Statistiek, Sociaal en Cultureel Planbureau. Armoedesignalement. Den Haag, Heerlen: Centraal Bureau voor de Statistiek, Sociaal en Cultureel Planbureau; 2011.

15. Tierolf B, Steketee M, Gilsing R, Bellaart H. Leefomstandigheden van kinderen met een migratieachtergrond. Utrecht: Kennisplatform Integratie \& Samenleving; 2017.

16. HuijnkW, Andriessen I. Integratiein zicht? Deintegratievan migranten in Nederland op acht terreinen nader bekeken. Den Haag: Sociaal en Cultureel Planbureau;2016. 